\title{
A comment on the MPI index
}

\author{
Jacques Silber
}

Published online: 6 August 2011

(C) Springer Science+Business Media, LLC 2011

Sabina Alkire and James Foster [3]'s review of their approach to multidimensional poverty measurement is a clear presentation of ideas they have presented and defended previously. Their AF index, especially its simplest form which they call "adjusted multidimensional headcount ratio" and which is the multidimensional poverty index used by Alkire and Santos [2] in their empirical paper, has certainly the advantage of clarity and simplicity, when compared to other multidimensional poverty indices. This is indeed what makes it extremely attractive, in addition to the fact that it has quite a nice number of appealing properties.

As emphasized by Rippin [8] there is however at least one (debatable) feature which the MPI index (and actually any AF index) does not have: it violates the axiom of Non-Increasingness under a Strong Inequality Decreasing Switch. In other words the MPI index will not decrease when the number of dimensions in which the poorer individual is deprived decreases. An additional missing property is that Alkire and Foster ignore substitutability and complementarity between dimensions, although in footnote 25 they explain why they disregarded this feature. Taking into account this element when there are more than two dimensions is in fact not a simple task but it may have very important policy implications. Duclos et al. [5], when discussing the case of complementarity between two dimensions, thus wrote that "better nourished children learn better" so that "overall poverty would decline by more if we were to transfer education from the poorly nourished to the better nourished."

To simplify the analysis of multidimensional poverty but keep its policy relevance, it could be useful to make a clear distinction between the number of dimensions to take into account when measuring deprivation and the number of variables to include when attempting to derive an index for each poverty dimension. Alkire [1] had stressed this point when she listed some of the questions that have to be raised

J. Silber $(\bowtie)$

Bar-Ilan University, Ramat-Gan, Israel

e-mail: jsilber_2000@yahoo.com 
when measuring multidimensional poverty ("How to choose domains or dimensions? How to choose relevant indicators for the domains? How to model the interaction among indicators and among dimensions?"). Ravallion [7]'s skepticism towards the MPI might be less relevant once the number of dimensions (domains) becomes small, even though the quantity of indicators included in each dimension might be quite high.

Which domain should a multidimensional approach to poverty comprise? Despite Sen's [9] forceful arguments in favor of including education, I tend to agree with Ravallion when he writes that ".....we can probably all agree that "health" is valued intrinsically, independently of command over commodities. However, it is more contentious that education has such an intrinsic value...."

As far as the selection of relevant variables for each dimension is concerned, one could imagine that there is a general consensus on which items to include, this being particularly true for the standard of living. McKay [6] argues however that, even in a country like the United Kingdom, there is no such a consensus and that there is a great deal of variation in different people's ideas of what is necessary. In fact "lack of 'necessities' almost invariably goes hand-in-hand with the presence of "non-necessities'." This is why van den Bosch [10] was in favor of a deprivation measure simply based on adding up the lack of items, the approach taken by the MPI and which amounts to using a "counting approach" to the measurement of multidimensional deprivation.

In short, I wonder whether it would not be useful to analyze multidimensional poverty in two stages, one where one counts the number of items each individual is deprived of, separately for each dimension, and another one where one looks at the distribution of deprivations in the various dimensions and evidently at the degree of correlation between the "dimension deprivations." In other words one would first compute an MPI-type index, separately for each dimension. Once the data are available, this is a simple task and it is probably more appealing than using principal components or some other multivariate analysis to derive a measure of individual deprivation for each dimension. But in a second phase, where the analysis is limited to a small number of deprivation dimensions, it is probably better to use a measure like the Bourguignon and Chakravarty [4] index that is more sophisticated than the MPI index and allows dimensions to be substitutes or complements.

\section{References}

1. Alkire, S.: Choosing dimensions: the capability approach and multidimensional poverty. In: Kakwani, N., Silber, J. (eds.) The Many Dimensions of Poverty. Palgrave Macmillan, London (2007)

2. Alkire, S., Santos, M.E.: Acute multidimensional poverty: a new index for developing countries. OPHI Working Paper No. 38, University of Oxford (2010)

3. Alkire, S., Foster, J.: Understandings and misunderstandings of multidimensional poverty measurement. J. Econ. Inequal. 9(2), 289-314 (2011)

4. Bourguignon, F., Chakravarty S.R.: The measurement of multidimensional poverty. J. Econ. Inequal. 1(1), 25-49 (2003)

5. Duclos, J.-Y., Sahn, D.E., Younger, S.D.: Robust multidimensional poverty comparisons. Econ. J. 116(514), 943-968 (2006)

6. McKay, S.: Poverty or preference: what do 'consensual deprivation indicators' really measure? Fisc. Stud. 25(2), 201-223 (2004)

7. Ravallion, M.: On multidimensional indices of poverty. J. Econ. Inequal. 9(2), 235-248 (2011) 
8. Rippin, N.: Poverty severity in a multidimensional framework: the issue of inequality between dimensions. Courant Research Center, Discussion Paper No. 47, University of Göttingen (2010)

9. Sen, A.: The importance of basic education, a speech to the commonwealth education conference, Edinburgh. http://people.cis.ksu.edu/ ab/Miscellany/basiced.html (2003)

10. Van den Bosch, K.: Using subjective information to correct biases in deprivation indices. In: Paper Prepared for the International Association for Research in Income and Wealth, Krakow, 27 August-2 September 2000 